\title{
Design of Pyrolysis Reactor for Waste Plastic Recycling
}

\author{
Wondwosen Bekele ${ }^{1}$, Wassihun Amedie ${ }^{2,3, ~}{ }^{*}$, Zelalem Salehudres ${ }^{1}$ \\ ${ }^{1}$ Department of Mechanical and Vehicle Engineering, School of Engineering, Adama Science and Technology University, Adama, Ethiopia \\ ${ }^{2}$ Department of Production Engineering, College of Engineering, Defence University, Bishoftu, Ethiopia \\ ${ }^{3}$ Engineering Department, Malawi Institute of Technology, Malawi University of Science \& Technology, Limbe, Malawi
}

Email address:

wondieb@gmail.com (W. Bekele),wassihun2015@gmail.com (W. Amedie),zmasresha4@gmail.com (Z. Salehudres)

${ }^{*}$ Corresponding author

To cite this article:

Wondwosen Bekele, Wassihun Amedie, Zelalem Salehudres. Design of Pyrolysis Reactor for Waste Plastic Recycling. Engineering and Applied Sciences. Vol. 5, No. 5, 2020, pp. 92-97. doi: 10.11648/j.eas.20200505.12

Received: September 1, 2020; Accepted: October 21, 2020; Published: November 4, 2020

\begin{abstract}
There is an increase in the production and consumption of plastics in day to day life. All plastics are disposed as waste after their usage. The need to intervene through proper disposal and management of waste plastics is very crucial. These call the use of thermal pyrolysis, which is a way of making these wastes to become very useful to us by recycling them to produce fuel oil. In this study, the pyrolysis reactor was design and manufactured for recycling of waste plastic into fuel working by the principle of thermal pyrolysis process. Three experiments are carried out to test the proper function of the reactor. It was found that about $84 \%$ of fuel obtained from one kilogram of plastic at temperature of $360^{\circ} \mathrm{C}$. The feed stock that was used for the experiment was plastic wastes of polyethylene with different proportion LDPE and HDPE. The method feeding the feedstock to the reactor was by opining the top cover of the reactor for every batch. The reactor was heating externally using furnaces built for the purpose and at the outlet of reactor the condenser is attached to condense the vapors coming out of it. The reactor temperature was controlled by thermocouple sensor fixed inside the reactor and this sensor connected to an external PD controller. A separation procedure of fuel was employed by controlling the internal temperature of the reactor. Three types of fuel obtained from these experiments which are similar to gasoil, kerosene and diesel temperature range from $130^{\circ} \mathrm{C}-230^{\circ} \mathrm{C}, 230^{\circ} \mathrm{C}-270^{\circ} \mathrm{C}$ and $230^{\circ} \mathrm{C}$ and above respectively. The fuel obtained from the experiment tested and characterized in national petroleum supply enterprise laboratory and meet the physical and chemical characteristic of fuels for different applications.
\end{abstract}

Keywords: Design, Manufacturing, Reactor, Fuel, Hydrocarbon, Plastics Wastes, Polyethylene, Pyrolysis, Temperature

\section{Introduction}

Economic growth and changes in the structure of consumption and production lead to a rapid increase in the production of plastic waste in the world. The world's annual plastic consumption has increased from about 1.5 million metric tons in 1950 to 270 million metric tons in 2010 and 359 million metric tons in 2018 [1]. The presence of plastic waste in a landfill can lead to poor air quality, because it is not biodegradable, it can remain in a landfill for hundreds of years. According to the environmental research organization, large amounts of plastic waste end up in the ocean, killing up to a million sea creatures each year when they mistake plastic for food. Every year, 500 billion plastic bags are used around the world, and after a while they are thrown into landfills, because plastic bag waste is very light, it can move freely to block the sewer and drainage system $[2,17]$.

On the other hand, recycling plastic waste can make it possible to collect and dispose of plastic waste in an environmentally friendly way, as well as turn it into a resource. This resource-saving goal is very important for most cities, where rapid industrialization and economic development put a lot of pressure on natural resources.

The conversion of plastic waste into hydrocarbon fuel materials is a well-known process. Many other processes, including pyrolysis and catalytic degradation, have been developed to depolymerize plastic waste into liquid hydrocarbon fuel. The purpose of this study is to design and manufacture a pyrolysis reactor for recycling plastic waste into fuel using widely studied scientifically based conversion processes. This technology makes it possible to recycle most 
types of plastic waste and convert it into liquid hydrocarbon fuel materials. Three conditions are needed to qualify a combustible substance to be designated as fuel, viz. utilization, efficiency and economics [3]. The first condition relates to its utility, that the energy released during combustion must be sufficient for use. Thus, materials that have a very low amount of combustible material that gives low calorific values cannot be called fuel. The second condition is the efficiency of material combustion and the recovery of its thermal energy for some application. Third, the amount of energy received must be economical to use, and the cost of the fuel material must be less than the cost of the heat energy received in order to qualify it as fuel. This high-quality fuel, converted from plastic waste, satisfied the conditions and has the potential to overcome many economic and environmental problems.

One of the challenges with mass recycling of plastic waste is the need for their collection, selection and processing. According to [4], the key problems and possible solutions for thermolysis of plastics are related to complex sorting and conversion technologies. It was recommended to use costeffective methods of pre-treatment/conversion of heterogeneous waste. The modular extruder for processing heterogeneous industrial plastic waste into homogeneous melt/pellets and the new integration of pre-processing and conversion are among promising technologies for bulk processing of plastic waste [4].

The effect of different catalytic on the mixture of polypropylene (PP) and polystyrene (PS) was investigated in a semi-batch reactor [5]. The use of zeolite catalyst produces an increase in the yield of liquid oil in thermal pyrolysis. The highest amount of gaseous products is produced by the use a natural clinoptilolite zeolite. The use of silica-alumina also showed good catalytic performance.

The engineering design and thermal analysis methods are applied from concept to experimental tests of the pyrolysis reactor.

The use of catalyst Alumina silica and Barium Carbonate with a proportion of polymer to catalyst ratio in the pyrolysis is $10: 1$ at a temperature range of $300^{\circ} \mathrm{C}-450^{\circ} \mathrm{C}$ yield liquid hydrocarbon product [6]. As the temperature increases, the influence of the nature of the catalyst becomes less significant.

According to the review [7], the ratio of mixed plastics consists of 75 wt.\% LDPE, 30 wt.\% HDPE and 24 wt.\% PP. The experiments were carried out at temperatures of $650^{\circ} \mathrm{C}$ and $730^{\circ} \mathrm{C}$ in a fluidized bed reactor. In this experiment, the product yield at a lower temperature of $650^{\circ} \mathrm{C}$.

\section{Process Description}

The pyrolysis process is widely studied in conversion of different residues to usable energy forms. The fast pyrolysis of rise husk, pyrolysis of safflower and pyrolysis of coconut and cashew nut shells are among many.

Rice husks were quickly pyrolysed at temperatures from $420^{\circ} \mathrm{C}$ to $540^{\circ} \mathrm{C}$ in a fluidized bed, and Bio-oil was obtained as the main product. The experimental result shows that the highest yield of bio-oil is 56 wt.\% - was obtained at a temperature of $465^{\circ} \mathrm{C}$ for rice husks. The chemical composition of the resulting bio-oil was analyzed by GC-MS and its calorific value, stability, Miscibility, and corrosion characteristics were determined. These results showed that the resulting Bio-oil can be directly used as fuel oil for combustion in a boiler or furnace without any modernization. In addition, the fuel can be recycled for use by vehicles. In addition, the energy efficiency of the pyrolysis process was analyzed. [8-10]

Pyrolysis is a thermochemical process, without the aid of a catalyst, for converting plastic waste by heating the feedstock at a high temperature in the absence of air, which produces gaseous products, and then condenses to produce a liquid fuel consisting of pyrolytic oil or liquid oil. Almost $70-80 \%$ of gaseous products are converted to liquid fuel, providing a good amount of liquid fuel. The reason for the popularity of this process is that it gets a good amount of liquid fuel from the feedstock, which has properties very similar to commercial transport fuels $[11,14]$.

The polymer structure of both low-density polyethylene (LDPE) and high-density polyethylene (HDPE) is a long chain of aliphatic hydrocarbons. Aliphatic hydrocarbons are hydrocarbons that do not contain benzene rings. The difference in density between LDPE and HDPE is due to its difference in the branching chain. LDPE has a large degree of branching of molecular chains, while HDPE has very little or no branching at all.

The density of LDPE and HDPE ranges from 910 to 925 $\mathrm{kg} / \mathrm{m}^{3}$ and from 940 to $965 \mathrm{~kg} / \mathrm{m}^{3}$, respectively [12]. The hardness of all polyethylene materials increases with increasing density. Dimensional stability and better physical properties of polyethylene will be achieved by increasing the density and depending on the temperature. The melting point of polyethylene ranges from $87.8^{\circ} \mathrm{C}$ to $121.2^{\circ} \mathrm{C}$ [12]. Lowdensity polyethylene begins to melt around $87.8^{\circ} \mathrm{C}$, where-as in HDPE - it begins at a temperature of about $121.2^{\circ} \mathrm{C}$. This means that HDPE is thermally more stable than LDPE. [13].

\section{Materials Used for the Experiment}

The following major experimental materials are applied for the conversion of plastic waste to fuel.

A. Low density polyethylene (LDPE): The choice of plastic samples was based on the most common ones found in the waste stream, such as commercial plastic bags, dispensing bottles, cream tubes, oil and chemical containers, and so on. High-density polyethylene Waste samples materials collected from the garbage yard of the vicinity. For the experiment, the collected HDPE waste is cut into small pieces. LDPE has a density range of $0.910 \mathrm{~g} / \mathrm{cm}^{3}-0.940$ $\mathrm{g} / \mathrm{cm}^{3}$ and is made from high-pressure ethylene oil. LDPE does not react at room temperature, except for strong oxidizing agents and some solvents that cause swelling. It has the ability to withstand temperatures of $80^{\circ} \mathrm{C}$ continuously and $95^{\circ} \mathrm{C}$ for a short time. The thermal decomposition of LDPE is very difficult if not impossible 
$[15,18]$.

B. Reactor: the reactor was made of mild steel that is sealed at one end and an exhaust tube at the other end that is connected to a three-section condenser. The internal volume of the reactor is $0.075 \mathrm{~m}^{3}$. It has a capacity of 75 liters of liquid fuel and a height of 1000 $\mathrm{mm}$ with a cylinder diameter of $165 \mathrm{~mm}$.

C. Furnace: the reactor Furnace was heated from the outside by placing it inside an electric furnace or charcoal. The furnace has a thermocouple for controlling the heating temperature.

D. Condenser: a condenser is attached to the reactor outlet to condense the vapors coming out of it. These three condensers are connected to each other by a pipe and immersed in a tank of up to 500 liters of water for efficient condensation. Gaseous hydrocarbons at a temperature of about $350^{\circ} \mathrm{C}$ condense to about $30^{\circ} \mathrm{C}-35^{\circ} \mathrm{C}$.

E. Control Panel: the entire process is controlled via the control panel.
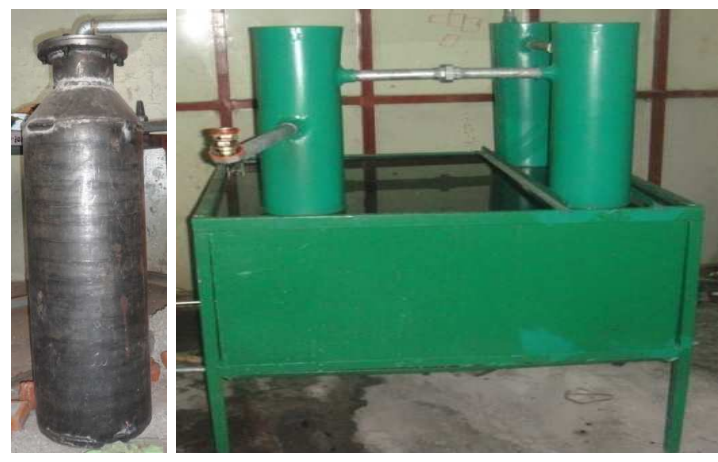

Figure 1. The design of the reactor, condenser and reactor cylinder cover plate.

\section{Experimental Procedure}

Structure of the extraction system

The fuel extraction system consists of a feed system, a pyrolysis reactor, a furnace, condensers, and a temperature controller, as shown in Figure 2. Waste plastics were loaded directly into the main reactor of pyrolysis. When the reactor
With the exception of standard parts such as valves, all parts of the reactor, condensers and other components are manufactured in accordance with optimal technological processes and using operating plans.

The design parameters were determined analytically [16] and the following results were obtained:

i) The internal volume of the reactor is $0.075 \mathrm{~m}^{3}$.

ii) Small diameter of reactor, $\mathrm{d}=165 \mathrm{~mm}$;

iii) Large diameter of reactor, $\mathrm{D}=330 \mathrm{~mm}$

iv) Intensity of internal pressure developing at the pyrolysis temperature of $430^{\circ} \mathrm{C}$ is $1.08 \mathrm{MPa}$

v) Number of cylinder cover bolts $=6$.

vi) The wall thickness of the reactor tank is in accordance with the standard that is available on the market.

vii) The flange of the cylinder is made of low-carbon steel with a permissible stress of $62 \mathrm{MPa}$ at a temperature of $430^{\circ} \mathrm{C}$.

Figure 1 shows a partial view of the designed reactor, the condenser, and the reactor cylinder cover.

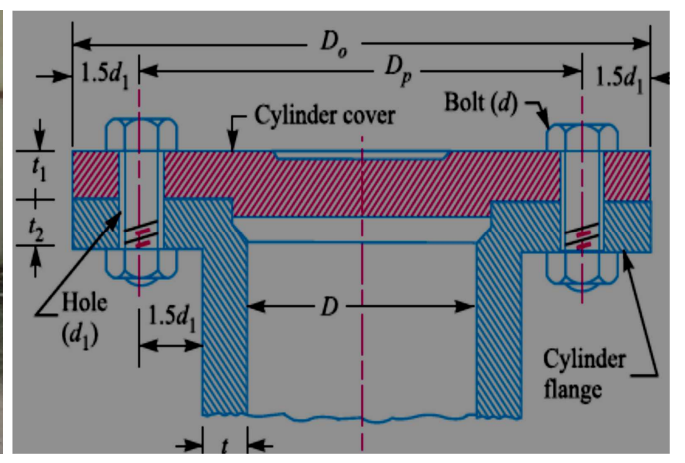

temperature rises, thermal pyrolysis begins, followed by molecular rearrangement. The temperature controller regulates the temperature and as a result homogenizes the feedstock. Pyrolysis is initiated to the point of gasification of the product. Non-plastic materials fall to the bottom of the reactor.

The gas goes through the pipe to the condensers for cooling.

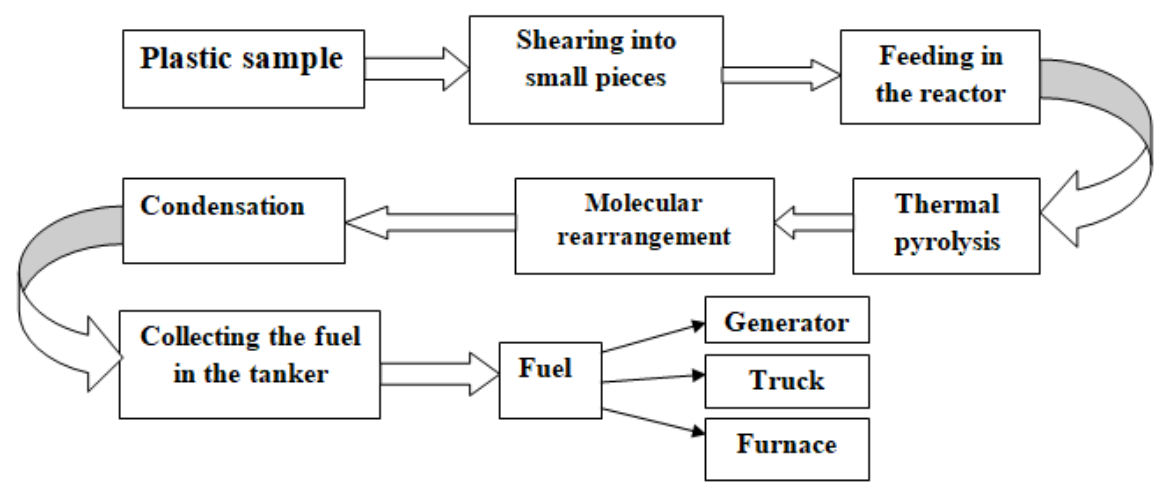

Figure 2. Extraction procedures of the thermal pyrolysis system.

\section{Test Procedure of pyrolysis}

Two pyrolysis tests were conducted. During the first pyrolysis, 18 kilograms of small pieces of $\mathrm{PE}$ with a 5:1 ratio of HDPE-LDPE were loaded onto the reactor for the thermal pyrolysis reaction. Then the reactor was heated at a rate of $1.65^{\circ} \mathrm{C} / \mathrm{min}$. the temperature reached $304^{\circ} \mathrm{C}$.

During the second pyrolysis, 14 kilograms of small pieces of PE with a ratio of 2.5: 1 of HDPE: LDPE were loaded into 
the reactor for the second thermal pyrolysis reaction. The reactor was heated at a rate of $2.75^{\circ} \mathrm{C} / \mathrm{min}$. to a temperature of $360^{\circ} \mathrm{C}$. For both tests the temperature range is control between $130^{\circ} \mathrm{C}-180^{\circ} \mathrm{C} ; 180^{\circ} \mathrm{C}-230^{\circ} \mathrm{C} ; 230^{\circ} \mathrm{C}-270^{\circ} \mathrm{C}$ and $270^{\circ} \mathrm{C}$ and above (Table 1 ).

The vaporized gas coming from the reactor was collected through a pipe to a condenser and finally collecting in a flask. The liquid product collected through the condenser was regulated based on temperature differences that prevent mixing of different types of fuel. The extracted fuel was weighed and its volume recorded for each pyrolysis operation. After the pyrolysis operation was completed, the solid residue remaining inside the reactor was weighed.

\section{Results and Discussions}

During the first thermal pyrolysis, it was noted that at a temperature of about $304^{\circ} \mathrm{C}$, the maximum yield of liquid product was obtained in the experiment. During thermal pyrolysis 2 , it was recorded that at a temperature of about $360^{\circ} \mathrm{C}$, the experiment obtained the largest amount of liquid product. In both tests the maximum yield is found with in temperature range of $270^{\circ} \mathrm{C}$ and above. The following table 1 shows the results obtained by thermal pyrolysis of 18 and 14 kilograms of polyethylene samples at different temperatures.

Table 1. Results of 18 and 14 kilograms of polyethylene sample at different temperature.

\begin{tabular}{llll}
\hline \multicolumn{4}{l}{ Thermal Pyrolysis of $\mathbf{1 8}$ kilograms of polyethylene sample at different temperature $\left({ }^{\circ} \mathbf{C}\right)$} \\
\hline Temperature $\left({ }^{\circ} \mathbf{C}\right)$ & weight of liquid Products $(\mathrm{g})$ & weight of solid Products after $304^{\circ} \mathbf{C}(\mathrm{g})$ & weight of gaseous Products after $304{ }^{\circ} \mathbf{C}(\mathrm{g})$ \\
\hline 130 & & & \\
180 & 100 & 3000 & \\
230 & 3200 & & \\
270 & 4000 & & \\
304 & 6000 & & \\
\hline
\end{tabular}

\begin{tabular}{|llll}
\hline \multicolumn{2}{|c|}{ Thermal pyrolysis of $\mathbf{1 4}$ kilograms of polyethylene sample at different temp $\left({ }^{\circ} \mathbf{C}\right)$} \\
\hline Temperature $\left({ }^{\circ} \mathbf{C}\right)$ & weight of liquid Products $(g)$ & $\begin{array}{l}\text { Weight of residue Products after } 360^{\circ} \mathbf{C} \\
(g)\end{array}$ & weight of gaseous Products after $360^{\circ} \mathbf{C}(\mathbf{g})$ \\
\hline 130 & 100 & & 1000 \\
180 & 1800 & 1300 & \\
240 & 4800 & & \\
270 & 5000 & & \\
360 & & & \\
\hline
\end{tabular}

As shown in Figure 3 and Figure 4, there is a tendency to change the temperature in relation to the output of the liquid product. In both tests, at $180^{\circ} \mathrm{C}$, the fuel began to yield and continued to increase linearly as the temperature increased. The difference in fuel yield is observed in both pyrolysis processes at temperatures from $270^{\circ} \mathrm{C}$ to $304^{\circ} \mathrm{C}$. At this point in temperature, the pyrolysis one fuel output continuously increased in the same rate at a lower temperature; while the fuel output remained constant for pyrolysis two after reaching to $270^{\circ} \mathrm{C}$ and the thermal pyrolysis process get halted at a temperature of $360^{\circ} \mathrm{C}$.

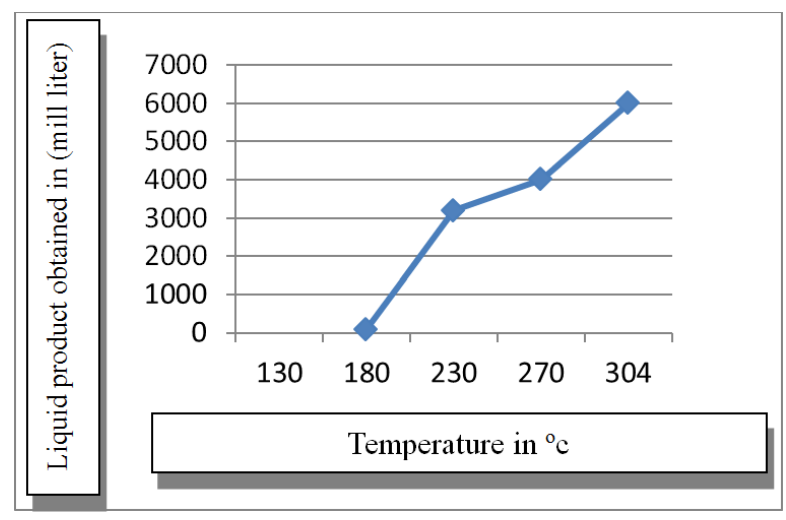

Figure 3. Temperature - yield of liquid product in thermal pyrolysis one.

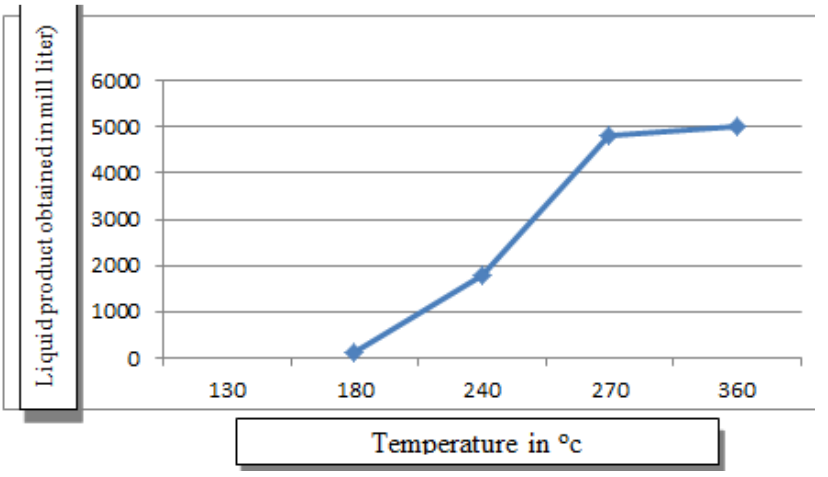

Figure 4. Temperature - yield of liquid product in thermal pyrolysis two.

The experiment depicted that pyrolysis one resulted $74 \%$ of liquid fuel, $9 \%$ of gaseous product and $17 \%$ of liquid residue. Likewise pyrolysis two resulted $84 \%$ of liquid fuel, $7 \%$ of gaseous product and $9 \%$ of liquid residue.

Increasing of the heating rate from $1.65^{\circ} \mathrm{C} / \mathrm{min}$ to $2.75^{\circ} \mathrm{C}$ $/ \mathrm{min}$, in which the second pyrolysis is conducted, make a yield change only at a temperature of $270^{\circ} \mathrm{C}$. Above this temperature the yield in first pyrolysis is more than the second test though the heating rate of the reactor is less than the second pyrolysis. The results show that higher liquid oil yield obtained at a temperature at $360^{\circ} \mathrm{C}$. In further increase of temperature the yield for liquid oil reduced and the gaseous product as it is reaching the process limit for thermal 
degradation of HDPE and LDPE.

It has been argued [6] that the inclusion of a larger amount of catalyst leads to a higher yield. Its result shown that the inclusion of barium carbonate and silica alumina as catalysts with a ratio of 10:1 yield is found at reaction temperatures in the range of $300^{\circ} \mathrm{C}$ to $450^{\circ} \mathrm{C}$. However this study was designed and conducted without the use of catalysts, to test the natural reaction of the main ingredients of HDPE and
LDPE wastes. The product yield temperature found significantly lower than the temperature using catalysts.

At high operating temperatures and high heating rates, pyrolysis increases the bond gap, which leads to the formation of smaller molecules. The rate of conversion increases with increasing temperature, and at this increased rate, gaseous products predominate over liquid products or outputs.

Table 2. The test report of National petroleum supply enterprise.

\begin{tabular}{|c|c|c|c|c|}
\hline SN & Property & $\begin{array}{l}\text { Test method } \\
\text { ASTM }\end{array}$ & Limit & $\begin{array}{l}\text { Test result } \\
\text { ASTUPFSG-3 }\end{array}$ \\
\hline 1 & Density@15C.g/ml & D 1298 & Report & 0.7886 \\
\hline \multirow[t]{5}{*}{2} & Density @ 20 $\mathrm{C} . \mathrm{g} / \mathrm{ml}$ & D 1298 & Report & 0.7849 \\
\hline & Distillation & D 86 & & \\
\hline & $\mathrm{IBP}^{\circ{ }^{\circ} \mathrm{C}}$ & & - & 60 \\
\hline & $10 \%$ volume, recovered, ${ }^{\circ} \mathrm{C}$ & & - & 133.5 \\
\hline & $40 \%$ volume, recovered, ${ }^{\circ} \mathrm{C}$ & & - & 257.0 \\
\hline \multirow[t]{5}{*}{3} & $50 \%$ volume, recovered, ${ }^{\circ} \mathrm{C}$ & & - & 277.5 \\
\hline & $82 \%$ volume & & & Checked \\
\hline & $90 \%$ volume, recovered, ${ }^{\circ} \mathrm{C}$ & & $282-362$ & - \\
\hline & $95 \%$ volume, recovered, ${ }^{\circ} \mathrm{C}$ & & - & - \\
\hline & FBP. ${ }^{\circ} \mathrm{C}$ & & Max.390 & 387 \\
\hline 4 & Flash point $(\mathrm{PCMM}),{ }^{\circ} \mathrm{C}$ & D 93 & Min.52 & 16 \\
\hline 5 & Copper strip corrosion $3 \mathrm{Hrs} @ 100^{\circ} \mathrm{C}$ & D130 & Max.No.3 & $1 \mathrm{~A}$ \\
\hline 6 & Cloud point & D2500 & $\operatorname{Max} .5^{\circ} \mathrm{C}$ & 19 \\
\hline 7 & Kinematic viscosity & D445 & Min.1.9 Max.4.1 & 2.13 \\
\hline 8 & Conradson carbon residue on $10 \%$ distillation residue & D189 & Max.0.35 & 0.05 \\
\hline 9 & ASTM color & D1500 & Max. 3 & 2 \\
\hline 10 & Water and sediment & D2709 & Max.0.05 & Nill \\
\hline 11 & Total acidity $\mathrm{mg} \mathrm{KOH} / \mathrm{g}$ & D974 & Report & 0.023 \\
\hline 12 & Ash content & D482 & Max.0.01 & 0.0013 \\
\hline
\end{tabular}

According to the review [7], an experiment on a pyrolysis reaction with a mass mixing ratio of 2.5:1 (LDPE: HDPE) in a fluidized bed reactor produced a liquid fuel at a temperature of $650^{\circ} \mathrm{C}$. However, the results of this study showed that at a ratio range of 2.5:1 - 5:1 (HDPE: HDPE) and at a maximum temperature of $360^{\circ} \mathrm{C}$, pyrolysis resulted liquid fuel which makes the reactor more energy efficient.

The extracted fuel was characterized by the national oil supply company according to the extraction temperature ranges given in Table 1. One of the test results of the sample designated as ASTUPFSD-3, which was extracted at a temperature of $270^{\circ} \mathrm{C}$ and above, is shown in table 2 . All the properties and characteristics of the extracted fuel are within the acceptable range of the standards which satisfy both operational and safety of the product.

\section{Conclusions}

The research depicted that during thermal pyrolysis of polyethylene, the yield of the liquid product increases with increasing temperature and the maximum yield is obtained at $270^{\circ} \mathrm{C}-360^{\circ} \mathrm{C}$. The fuel separation procedure was applied by regulating the internal temperature of the reactor. The temperature control method plays a vital role on quality of liquid fuel, otherwise the fuel is mixed. Tertiary recycling of plastic waste by pyrolysis is a promising method for converting liquid fuels, yielding about $84 \%$ extraction. According to the results of tests conducted by the national oil supply company, the liquid product obtained in the temperature range of $130^{\circ} \mathrm{C}-230^{\circ} \mathrm{C}$ is similar to gas oil, and the liquid product obtained in the temperature range of $230^{\circ} \mathrm{C}-270^{\circ} \mathrm{C}$ is similar to kerosene and from the temperature range above $230^{\circ} \mathrm{C}$ has similar characteristics of diesel fuel.

The designed pyrolysis reactor is used not only for recycling of waste plastic but also for pyrolysis of biomass. The noncondensable flue gas produced during pyrolysis can be injected back to the reactor to enhance the pyrolysis reaction that results reduction of energy consumption and production time.

Therefore, these studies are considered appropriate and promising for converting plastic waste into fuel and protecting against environmental degradation.

\section{References}

[1] https://www.statista.com/statistics/282732/global-productionof-plastics-since-1950/.

[2] Kamisky, W., (1992), pyrolysis of polymers. Emerging Technologies in plastic recycling, Ed. G. D. S. Andrews, P. M., and Washington, DC: American Chemical Society.

[3] Gupta, O. P., Elements of Fuels, Furnaces and Refractories, Khanna Publishers, Delhi, 2005. 
[4] Anja Oasmaa (2019), Pyrolysis of plastic waste: opportunities and challenges, Engineering Conferences International, ECI Digital Archives, Pyrolysis and Liquefaction of Biomass and Wastes proceedings, VVT, Finland.

[5] Kim JR, Yoon JH, Park DW. (2002), Catalytic recycling of the mixture of polypropylene and polystyrene. Polymer Degradation and Stability, 2002, Pages 61-67.

[6] Dinish Chacko, et al. (2016), plastic Waste to fuel: A Sustainable method for waste Management, International Journal of Scientific \& Engineering Research, Volume 7, Issue 3.

[7] Anandhu Vijaya, kumar, Jilse Sebastian, (2018), Pyrolysis process to produce fuel from different types of plastic - a review, IOP Conf. Series: Materials Science and Engineering.

[8] Ji-Lu, Z., 2007. Bio-oil from fast pyrolysis of rice husk: Yields and related properties and improvement of the pyrolysis system. Journal of Anal. Appl. Pyrolysis.

[9] S. Sensoz and D. Angın, 2007 "Pyrolysis of safflower (Charthamustinctorius L.) seed press cake in a fixed-bed reactor: Part 2. Structural characterization of pyrolysis biooils" Journal of Bio-resource Technology.

[10] J. T. Alberto, Weihong Yang, Wlodzimierz Blasia, 2006, "Pyrolysis characteristics and global kinetics of coconut and cashew nut shells," Fuel Processing Technology, vol 87.

[11] David A. Katz, (1998), identification of polymers. Chemist, Educator, Science Communicator, and Consultant.
[12] Meier, JF, 1996, 'Fundamentals of Plastics and Elastomers', in CA Harper (ed), Handbook of Plastics, Elastomers, and Composites, McGraw-Hill, New York.

[13] Sorum, L, Gronli, MG \& Hustad, JE (2001), 'Pyrolysis characteristics and kinetics of municipal solid wastes', Fuel, vol. 80 , no. 9 .

[14] Masuda, T. T., T., (2006), Development of a process for the continuous conversion of waste plastics mixtures to fuel. Feedstock recycling and pyrolysis of waste plastics, Ed. J. K. Sheirs, W., Chichester: John Wiley \& Sons. 161-192.

[15] Jong Jin Park, Kwinam Park, Jin-Won Park and Dong Chan Kim, 2002, Characteristics of LDPE Pyrolysis, Korean Journal of Chemical Engineering volume 19, Article number: 658 .

[16] Shigley J., Mischke C., Budynas R. \& Nisbett K., "Mechanical Engineering Design", 8th ed., Tata McGraw-Hill, 2008.

[17] Pinakin Mehta ENVIS, (2004), Newsletter-6 Management of plastic, polymer wastes and Bio-polymer and impact of plastic on the eco-system volume 2 .

[18] Osueke, C. O. I. O. Ofondu (2010) "conversion of waste plastics (polyethylene) to fuel by means of pyrolysis international journal of advanced engineering sciences and technologies vol no. 4, issue no. 1, $021-024$. Publication, New York. 